\title{
Evaluation of Mechanical Properties of Wood Particles Reinforced Polymer Composites
}

\author{
H. V. Divya ${ }^{1, *}$, H. M. Kavya ${ }^{2}$, D. Saravana Bavan ${ }^{2}$, B. Yogesha ${ }^{1}$ \\ ${ }^{1}$ Malnad College of Engineering, Hassan, Visvesvaraya Technological University, Belagavi, Karnataka, India \\ ${ }^{2}$ Dayananda Sagar University, India
}

Copyright $(\mathrm{C} 2018$ by authors, all rights reserved. Authors agree that this article remains permanently open access under the terms of the Creative Commons Attribution License 4.0 International License

\begin{abstract}
Natural fiber composites are more attractive due to their high specific strength and lightweight. The focus in this work has been to study the influence of wood fibres on the mechanical properties of the polymer composites manufactured by extrusion and injection moulding process. Tensile and flexural tests were conducted to evaluate the tensile and flexural properties of the compounded composites. The interfacial properties, internal cracks are evaluated by using Scanning Electron Microscope. The results indicate flexural strength of the wood plastic composites increases with decrease in wood particles content. The tensile strength of pure plastic blend is higher compared to wood plastic composites.
\end{abstract}

Keywords Polypropylene, High Density Polyethylene, Injection Moulding, Mechanical Properties

\section{Introduction}

Polymer composites are the class of composite materials for structural applications. Polymer composites are often used as the substitute for the metal based ones in the mechanical industries [1]. They are used in the penal of solar boards, automobile accessories, polymer gears, body of modern cars, sports ratchets etc. [2]. Natural fibre reinforced polymer based composite materials are new class of engineering materials. The development of natural fiber composite materials has been a hot topic recently due to the increasing environmental awareness. Natural fibers are one such proficient material which replaces the synthetic materials and its related products for the light weight and high strength applications. The advantages of natural fiber composites include lightweight, low- energy production, and environmental friendly [3]. The use of natural fibers reduces weight by $10 \%$ and lowers the energy needed for production by $80 \%$, while the cost of the component is $5 \%$ lower than the comparable fiber glass-reinforced component [4]. Interest in this area is rapidly growing both in terms of their industrial applications and fundamental research as they are renewable, cheap, completely or partially recyclable, and biodegradable [5]. The application of natural fiber reinforced polymer composites and natural-based resins for replacing existing synthetic polymer or glass fiber reinforced materials in huge [6]. In the plastic-based composites, the polymers, thermoplastics, act as a matrix and flour of wood or other natural flour are reinforcement [7].

Wood-plastic composite (WPC) is a very promising and sustainable green material to achieve durability without using toxic chemicals. The term WPCs refers to any composites that contain plant fiber and thermosets or thermoplastics. In comparison to other fibrous materials, plant fibers are in general suitable to reinforce plastics due to relative high strength and stiffness, low cost, low density, low $\mathrm{CO} 2$ emission, biodegradability and annually renewable [8]. Nicole M. Stark. et.al, studied that Commercial wood flour, the most common wood-derived filler for thermoplastics, is produced in a mixture of particle sizes and generally has a lower aspect ratio than wood and other natural fibers. To understand how wood flour and fiber characteristics influence the mechanical properties of polypropylene composites, we first investigated the effect of different sizes of wood flour particles on the mechanical properties of wood-flour-filled polypropylene composites [9]. Qiangyuan.et.al, studied the properties of wood plastic composite (WPC). WPC with high modulus and impact strength were manufactured by combining polyethylene (PE) or polypropylene (PP) with wood fiber (WF) using twin-screw extruder techniques. The advantage of using low melt viscosity polymer matrices is that it enhances the modulus and reduces the overall viscosity of the system. SEM analysis of the composites indicates that the polymer molecules penetrate into the vessels and cracks of the cellulose fiber, which decreases the number of voids and produces a higher 
density composite with improved mechanical performance. The addition of maleic anhydride-grafted polyolefin as a compatibilizer improves the level of adhesion between the wood fiber and the polyolefin matrix. The earliest woodplastic composites appeared nearly a century ago where wood flour was combined with phenol-formaldehyde resin to create a composite material used as an automobile gearshift knob [10].

The present work focuses on wood-plastic composites manufactured from thermoplastic polymers and wood flour.

\section{Materials and Methods}

\subsection{Materials}

Teak wood fibres from wood industry scrap are obtained from southern part of India were used as the reinforcement. Polypropylene of grade AM 650 and High Density Polyethylene were used as the matrix. Maleic anhydride used as the coupling agent. The properties of reinforcement, matrix and coupling agent were shown in Table 1.

Table 1. Properties of reinforcement, matrix and coupling agent

\begin{tabular}{|c|c|}
\hline Wood fiber & Hard wood flour, Size: $150 \mu \mathrm{m}<\mathrm{D}>300 \mu \mathrm{m}$ \\
\hline Polypropylene(PP) & $\begin{array}{c}\text { Density: } 0.9 \mathrm{~g} / \mathrm{cm} 3, \text { Melting } \\
\text { temperature: } 1600 \mathrm{C}, \text { Melt flow index: } \\
20 \mathrm{~g} / 10 \mathrm{~min}\end{array}$ \\
\hline $\begin{array}{c}\text { High density } \\
\text { polyethylene } \\
\text { (HDPE) }\end{array}$ & $\begin{array}{c}\text { Density : } 0.95 \mathrm{~g} / \mathrm{cm} 3 \text {, Melting temperature : } \\
1900 \mathrm{C}, \text { Melt flow index: } 17.5 \mathrm{~g} / 10 \mathrm{~min} .\end{array}$ \\
\hline Maleic anhydride & $\begin{array}{c}\text { Density : } 1.48 \mathrm{~g} / \mathrm{cm}^{3} \text { Melting temperature : } \\
52.6^{\circ} \text { Melt flow index: } 1.1 \mathrm{~g} / 10 \mathrm{~min}\end{array}$ \\
\hline
\end{tabular}

\subsection{Processing of Composites by Twin Screw Extruder.}

Teak wood flakes obtained from wood industry scrap were initially grinded to obtain a mixture of various sizes. The grinded flakes were sieved using a sieving machine to obtain particles of desired dimensions. The required flour were obtained by passing through 600 microns sieve and retained in 300 microns sieve (Figure 1). The wood particles were then dried using a hot air oven for a period of 8 hours at a temperature of $800 \mathrm{C}$ to remove the absorbed moisture.

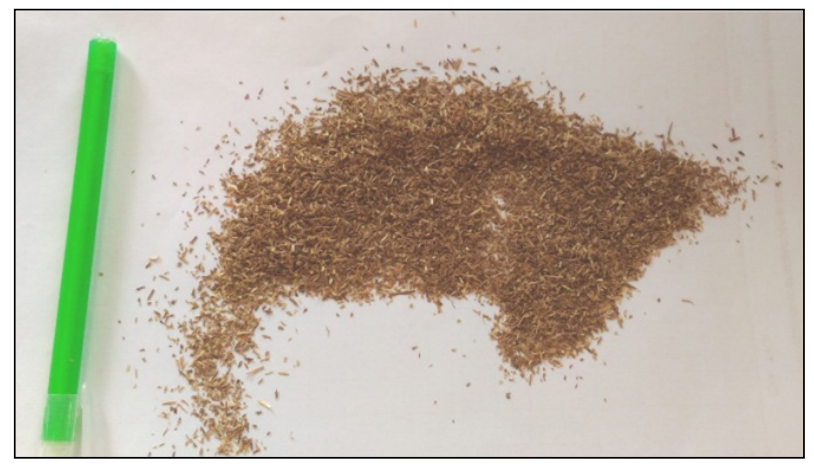

Figure 1. Wood fibres
A blend of PP and HDPE were hand mixed in the ratio $1: 4(20 \%$ and $80 \%$ by weight respectively). The material compositions in weight percentage are reported in the Table 2. All the materials were dried at $85^{\circ} \mathrm{C}$ for $48 \mathrm{~h}$ to avoid plasticization, hydrolyzing effects from humidity and to obtain the sufficient homogeneity. The materials were mixed and the mixture was extruded using co-rotating twin screw extruder (Make: CMEI, Model: 16CME, SPL, chamber size $70 \mathrm{cc}$ ) (Figure 2). The temperature maintained in three zones of the extruder barrel were at $1800 \mathrm{C}, 1820 \mathrm{C}, 1840 \mathrm{C}$ respectively and the temperature at the die was set at $1850 \mathrm{C}$. The extruder screw speed was set at $100 \mathrm{rpm}$ which yielded a feed rate of $5 \mathrm{~kg} / \mathrm{h}$. The extruded material was obtained in the form of a cylindrical wire which was quenched in cold water and then palletized. Before compounding, all the pallets were dried at $100^{\circ} \mathrm{C}$ in vacuum oven for $24 \mathrm{~h}$. The tensile test specimen of dimension $115 \mathrm{~mm} \times 19 \mathrm{~mm} \times 3 \mathrm{~mm}$ (ASTM D638) and flexural test specimen of dimension $90 \mathrm{~mm} \times 10 \mathrm{~mm} \times 3 \mathrm{~mm}$ (ASTM D790) were injection moulded from the wood polymer composites pellets using an Engel E-victory 30 with a 30 ton clamping force. The screw diameter is $22 \mathrm{~mm}$ with an L/D ratio of 30. Parameters of injection moulding are shown in table 3 .

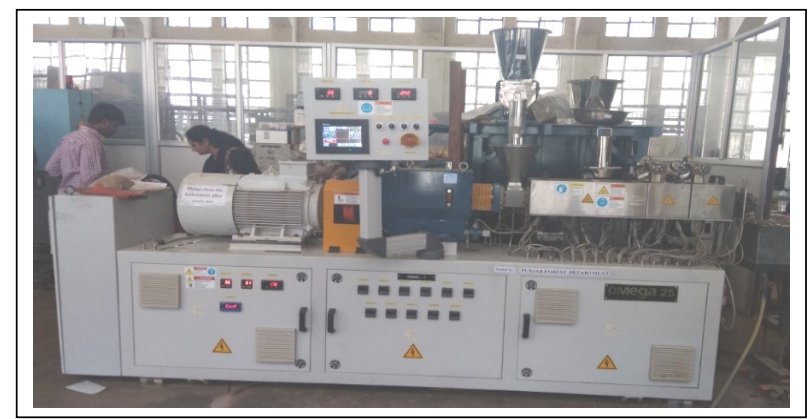

(Curtsey: Institute of wood science and Technology, Bengaluru, India)

Figure 2. Twin Screw extruder

Table 2. Formulations of composite in weight percentage

\begin{tabular}{|c|c|c|c|}
\hline $\begin{array}{c}\text { Composite } \\
\text { Batch }\end{array}$ & $\begin{array}{c}\text { PP/HDPE } \\
\text { Blend } \\
\text { (Weight in \%) }\end{array}$ & $\begin{array}{c}\text { Wood Fiber } \\
\text { (Weight } \\
\text { in \%) }\end{array}$ & $\begin{array}{c}\text { Maleic Anhydride } \\
\text { (Weight in \%) }\end{array}$ \\
\hline D1 & 100 & 0 & 0 \\
\hline D2 & 48 & 50 & 2 \\
\hline D3 & 58 & 40 & 2 \\
\hline D4 & 68 & 30 & 2 \\
\hline
\end{tabular}

Table 3. Parameters of injection moulding

\begin{tabular}{|c|c|}
\hline Barrel temperature (0C) & 226.7 \\
\hline Injection speed (mm/s) & 130 \\
\hline Injection pressure (bar) & 150 \\
\hline Holding pressure (bar) & 60 \\
\hline Holding time (s) & 3 \\
\hline Cooling time (s) & 60 \\
\hline Shot volume (cm3) & 22.5 \\
\hline
\end{tabular}




\subsection{Tensile Test}

The tensile properties of composites were evaluated using a Universal Testing Machine (Bangalore Integrated System Solutions) according to ASTM D638-03 standards. The tests were performed at constant strain rate of $2.5 \mathrm{~mm} / \mathrm{min}$. In every formulation 5 composites were tested and average is determined and noted. The load is applied until the specimen breaks and corresponding stress $\mathrm{v} / \mathrm{s}$ strain curves were generated. Figure 3 shows the tensile testing setup. In tensile test, a uniaxial load was applied through both ends. Tensile test specimens are shown in the figure 4 .

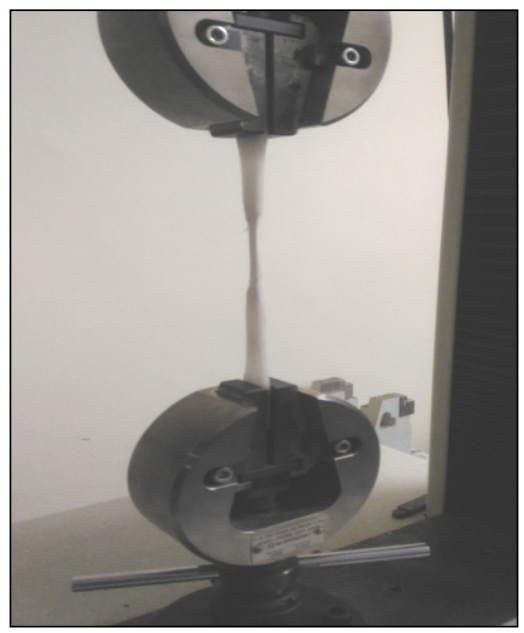

Figure 3. Loading arrangements for tensile test specimen

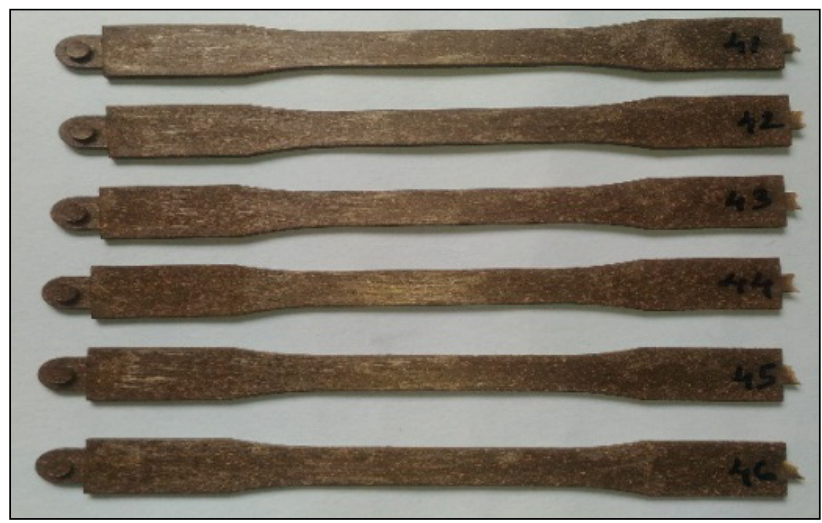

Figure 4. Tensile test specimens of D4 type formulation

\subsection{Flexural Test}

The flexural properties of WPCs were tested in a three point flexural setup (Figure 5) using BISS Universal Testing Machine (UTM) according to ASTM D790. The cross head speed was $2.0 \mathrm{~mm} / \mathrm{min}$. Test specimens were placed in between two supports with a span length of $70 \mathrm{~mm}$ and the load applied until the specimen breaks and corresponding stress $\mathrm{v} / \mathrm{s}$ strain curves generated by data acquisition software. Flexural test specimens are shown in the figure 6 .

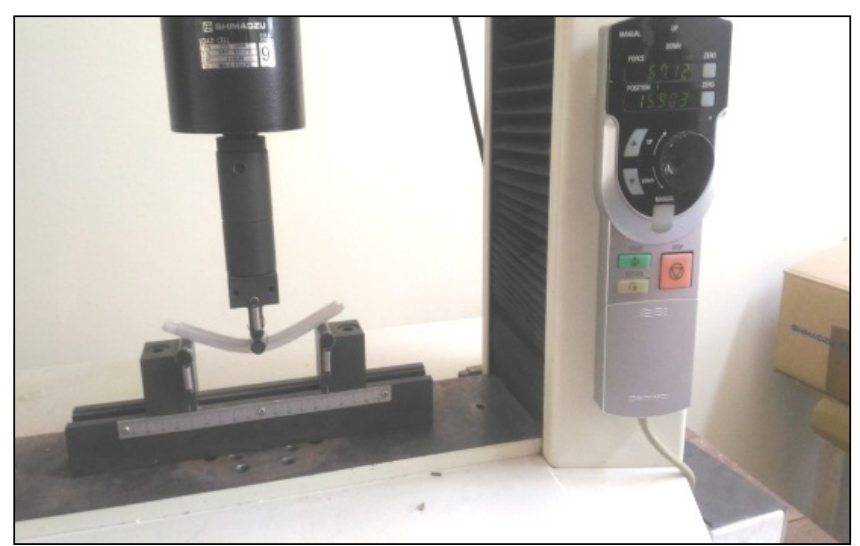

Figure 5. Loading arrangements for flexural test specimen

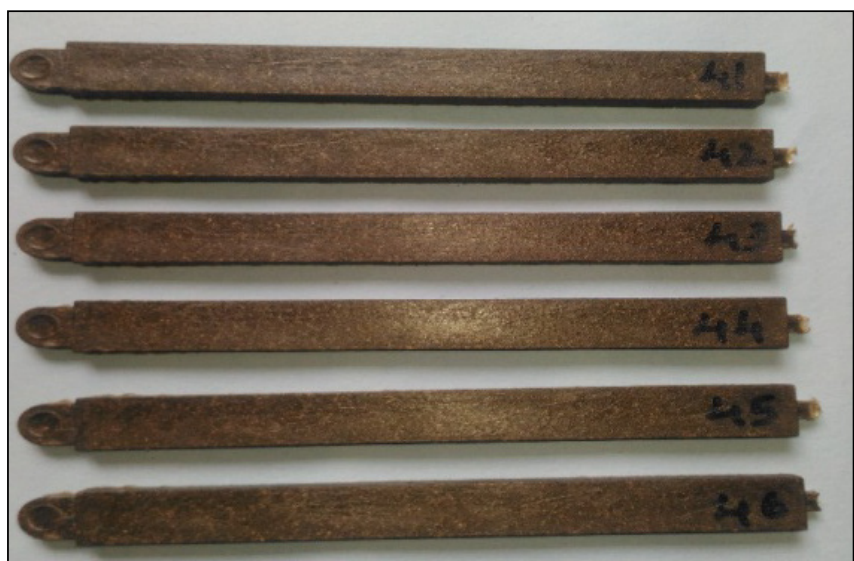

Figure 6. Flexural test specimens of D4 type formulation

\subsection{Scanning Electron Microscopy}

The surface characteristics of the composite material used for the investigation is studied through SEM. A scanning electron microscope (Carl Zeiss EVO 18) was used with an accelerated voltage of $20^{\circ} \mathrm{kV}$ and magnification of $300 \times$ for visualization of fractured surfaces of test specimens. In order to avoid the accumulation of electrical charges during examination, the sample was covered with a thin gold layer.

\section{Results and Discussions}

\subsection{Tensile Test Results}

The composite specimens D1, D2, D3\&D4 were tested for tensile properties in UTM. The results of the tensile strength and tensile modulus of the composites are given in the table 4 . Corresponding stress v/s strain graph is shown in the figure 7. As it can be seen from the table the tensile strength of the composites lie in the range 19.563-13.621MPa depending upon composite formulation. 
Table 4. Tensile properties of the composites

\begin{tabular}{|c|c|c|c|}
\hline $\begin{array}{c}\text { Composite } \\
\text { Batch }\end{array}$ & $\begin{array}{c}\text { Peak } \\
\text { Load(N) }\end{array}$ & $\begin{array}{c}\text { Ultimate Tensile } \\
\text { Strength (MPa) }\end{array}$ & $\begin{array}{c}\text { Tensile } \\
\text { Modulus } \\
\text { (GPa) }\end{array}$ \\
\hline D1 & 763 & 19.563 & 1.032 \\
\hline D2 & 531 & 13.621 & 2.646 \\
\hline D3 & 549 & 14.528 & 2.559 \\
\hline D4 & 567 & 14.826 & 1.959 \\
\hline
\end{tabular}

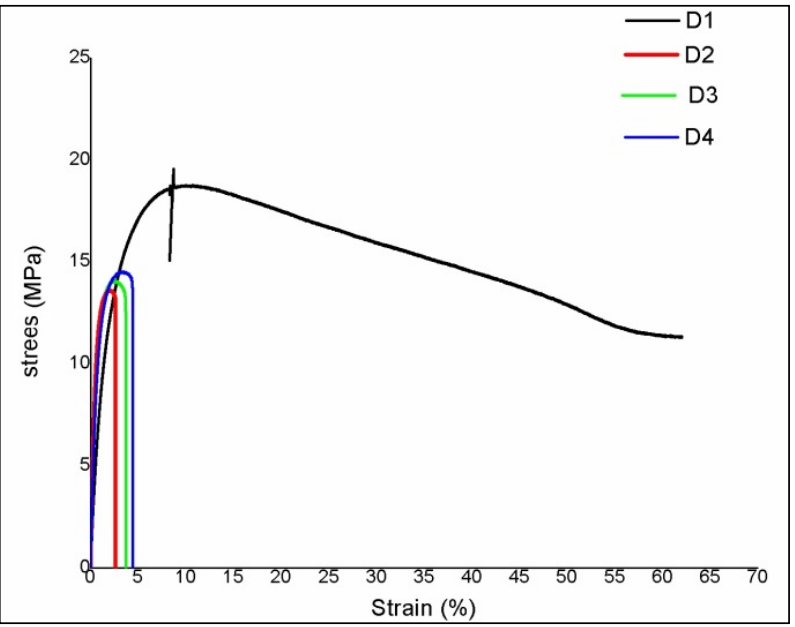

Figure 7. Stress v/s Strain graph of tensile test

The tensile strength of D1 (blend of PP and HDPE) is 19.563MPa and withstands a load of $763 \mathrm{~N}$. Among the three formulations of wood plastic composites i.e. D1, D2, D3, the D4 formulation exhibited higher tensile strengthof 14.826MPa. The D2 has the lower tensile strength of 13.621MPa. The composite D4 withstand the higher load of $567 \mathrm{~N}$.

\subsection{Flexural Test Results}

The ultimate flexural strength (UFS), flexural modulus and load are tabulated in the table 5 . The stress $\mathrm{v} / \mathrm{s}$ strain curve is shown in the figure 8. The flexural strength of D1 (blend of PP and HDPE) is $21.906 \mathrm{MPa}$ and withstands a load of $134 \mathrm{~N}$. Among the three formulations of wood plastic composites (D2, D3\&D4) the composites D4 exhibited higher flexural strength of $24.724 \mathrm{MPa}$ and capable to withstand the load of 151N. The composites D2 have the lower flexural strength of $21.103 \mathrm{MPa}$ and withstands load of $129 \mathrm{~N}$.

Table 5. Flexural properties of the composites

\begin{tabular}{|c|c|c|c|}
\hline $\begin{array}{c}\text { Composite } \\
\text { Batch }\end{array}$ & $\begin{array}{c}\text { Peak Load } \\
(\mathrm{N})\end{array}$ & $\begin{array}{c}\text { Ultimate Flexural } \\
\text { Strength (MPa) }\end{array}$ & $\begin{array}{c}\text { Flexural } \\
\text { Modulus (GPa) }\end{array}$ \\
\hline D1 & 134 & 21.906 & 0.642 \\
\hline D2 & 129 & 21.103 & 1.941 \\
\hline D3 & 133 & 21.802 & 2.389 \\
\hline D4 & 151 & 24.724 & 1.792 \\
\hline
\end{tabular}

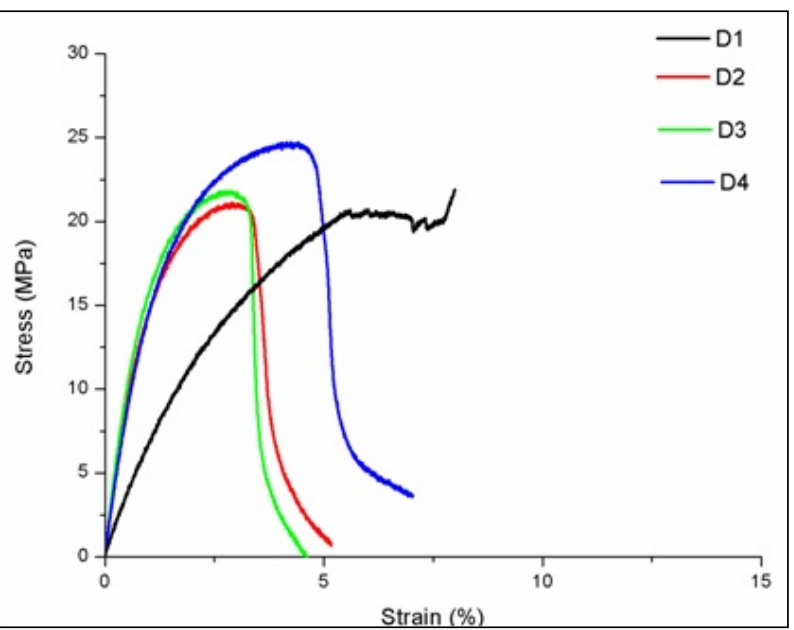

Figure 8. Stress v/s Strain graph of tensile test

\subsection{Microscopic Analysis by SEM}

The SEM analysis has been carried out to study the failure surfaces of composite structure, particularly to examine the fibre/matrix interaction, void content, and fibre pull out of the specimens. The tensile strength of D1 specimen is $24.61 \mathrm{MPa}$ and this decreases with increase in wood fibre reinforcement content. This may be due to poor interfacial bonding.

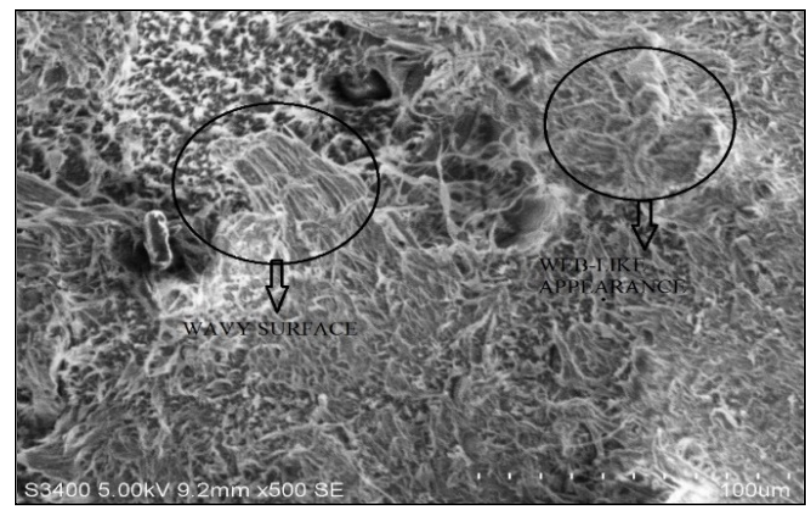

Figure 9. SEM analysis of D1 sample

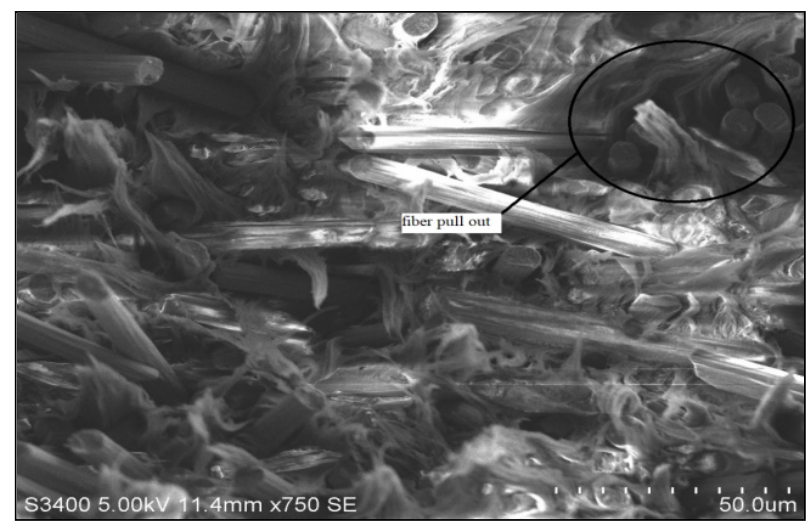

Figure 10. SEM analysis of D2 sample 


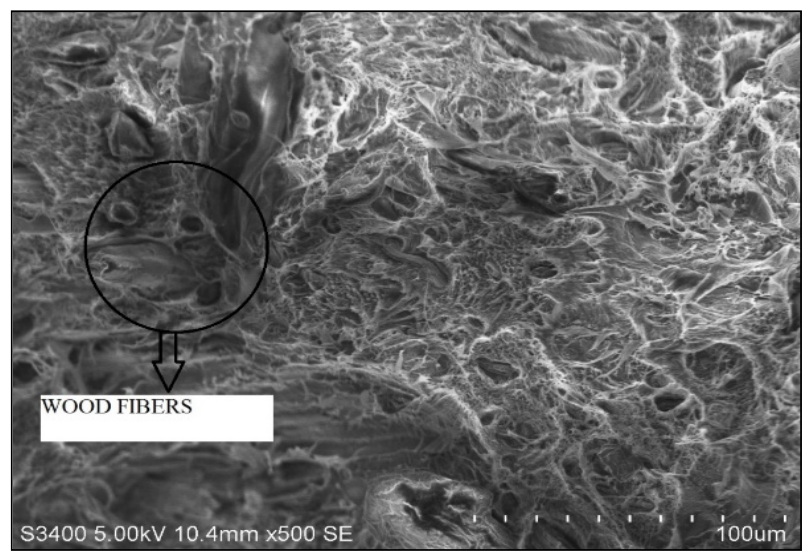

Figure 11. SEM analysis of D3 sample

From SEM analysis, fractographic images were obtained and analysed. From Figure 9, it is attributed that the material is ductile due to the presence of wavy surfaces and web-like structure. Figure 10 indicates the presence of fibre pull-out due to poor bonding between matrix and reinforcement. From Figure 11, it is clearly evident that the material has good adhesive bonding due to the absence of fibre pull-outs and voids. Figure 12 shows good dispersion of wood particles in the matrix to provide homogeneous properties throughout the material.

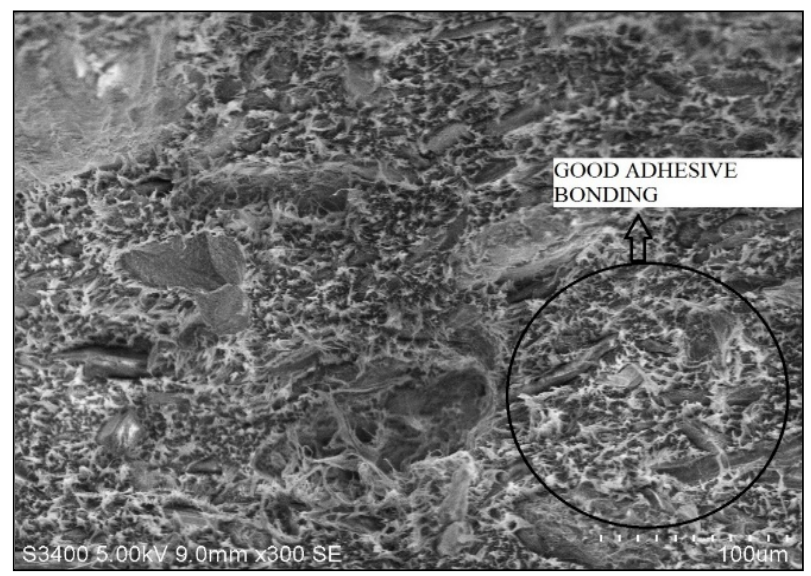

Figure 12. SEM analysis of D4 sample

\section{Conclusions}

The composites are made using blend of PP and HDPE as matrix, wood particles as reinforcement and maleic anhydride. Mechanical properties are evaluated and following conclusions were drawn.

The composite D1 made of pure PP and HDPE blend exhibits higher tensile of $19.563 \mathrm{MPa}$ and flexural strength of $21.906 \mathrm{MPa}$.

Composite D2 exhibited poor tensile strength.Among three wood plastic composites i.e. D2, D3 and D4, the D4 composites with less wood particle reinforcement exhibited highest flexural strength. Hence flexural strength increases with decrease in wood particle reinforcement.

It is evident from the flexural test results that flexural strength of wood plastic composites D4 is much higher in comparison with pure plastic blend D1.

From the SEM analysis, it is attributed that the material is ductile due to the presence of wavy surfaces and web-like structure. A Good dispersion of wood particles in the matrix is observed to provide homogeneous properties throughout the material.

\section{REFERENCES}

[1] Lingesh, B. V., et al. "Hybridization effect of fibers on mechanical properties of PA66/PP blend-based thermoplastic composites." Advanced Composites and Hybrid Materials(2018): 1-11.

[2] Divya, H. V., Naik, L. L., \&Yogesha, B. (2016). Processing techniques of polymer matrix composites-A review. Int. J. Eng. Res. General Sci, 4, 357-62..

[3] N Venkateshwaran, AElayaPerumal, A Alavudeen, M Thiruchitrambalam (2011). Materials and Design 32, pp. 4017-4021.

[4] Arpitha, G. R., \&Yogesha, B. (2017). An overview on mechanical property evaluation of natural fiber reinforced polymers. Materials today: Proceedings, 4(2), 2755-2760.

[5] Sanjay, M. R., \&Yogesha, B. (2017). Studies on natural/glass fiber reinforced polymer hybrid composites: An evolution. Materials Today: Proceedings, 4(2), 2739-2747.

[6] Ramesh, M., Palanikumar, K., \& Reddy, K. H. (2013). Mechanical property evaluation of sisal-jute-glass fiber reinforced polyester composites. Composites Part B: Engineering, 48, 1-9.

[7] Bhaskar, Jitendra, ShamsulHaq, and S. B. Yadaw. "Evaluation and testing of mechanical properties of wood plastic composite." Journal of Thermoplastic Composite Materials 25.4 (2012): 391-401.

[8] Ashori, A. (2008). Wood-plastic composites as promising green-composites for automotive industries!.Bioresource technology, 99(11), 4661-4667.

[9] Stark, N. M., \&Rowlands, R. E. (2003). Effects of wood fiber characteristics on mechanical properties of wood/polypropylene composites. Wood and fiber science. Vol. 35, no. 2 (2003): Pages 167-174.

[10] Yuan, Q., Wu, D., Gotama, J., \& Bateman, S. (2008). Wood fiber reinforced polyethylene and polypropylene composites with high modulus and impact strength. Journal of Thermoplastic Composite Materials, 21(3), 195-208. 